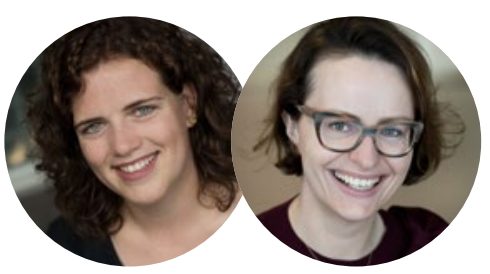

\title{
REDACTIONEEL
}

ANNE ESKES \& CATHARINA VAN OOSTVEEN

\section{De lessen van 2020}

Het is na drie jaar een traditie om telkens in het laatste TvZ-nummer terug te blikken op het afgelopen jaar. In 2019 eindigden wij met een reflectie op het debacle van de Wet BIG II. Dit jaar kunnen we niet om COVID-19 heen. lets wat wij niet voorzien hadden. Eind januari bezochten we nog het congres van de European Association of Nursing Science (EANS) in Milaan. COVID-19 was voor ons een ver-van-mijn bed-show. Het speelde uiteraard al in China en we zagen wat mensen met een mondkapje in het vliegtuig heen en terug, maar wij waanden ons - hoe naïef - veilig. Drie weken later was de regio rondom Milaan de eerste in Europa die in totale lock-

down ging en de rest van het verhaal is bekend.

Hoewel COVID-19 nog wel een poosje onder ons blijtt en veel collega's nog niet zijn hersteld van de hoge werk- en emotionele druk in coronatijd, heeft het ons ook veel geleerd en opgeleverd. Zo hebben digitale innovatie en regionale samenwerking tussen zorginstellingen een vlucht genomen en er mede voor gezorgd dat we nu COVID-zorg en reguliere zorg combineren. Het optimaliseren van de arbeidsomstandigheden van verpleegkundigen door onder andere betere positionering en zeggenschap zijn het gesprek van de dag, nu meer dan ooit zichtbaar is wat verpleegkundigen doen en hoe belangrijk ze zijn. Ook is de instroom van nieuwe verpleegkundestudenten groter dan ooit. Laten we hopen dat dit straks allemaal nieuwe collega's worden.

In COVID-19-tijd verschijnt ook een nieuw boek van onze hand: Onderzoek langs de meetlat - Onderzoekdesigns voor verpleegkundigen. De titel bevat een verwijzing naar de TVZrubriek De Meetlat. In de afgelopen jaren kregen wij veel positieve reacties van lezers op deze rubriek. We hebben daarom eerdere en nog niet gepubliceerde 'meetlatten' gebundeld. In de nieuwe teksten leggen experts veelvoorkomende onderzoekdesigns in verpleegkundig onderzoek uit met herkenbare praktijkvoorbeelden. Het boek biedt daarmee praktische handvatten voor het vertalen van wetenschap naar praktijk. Geïnteresseerden kunnen binnenkort aan de slag, want het verschijnt begin 2021. Als TVZ-redactie wensen wij je een goed uiteinde en een voorspoedig nieuwjaar met spin-off van alle geleerde lessen in 2020: meer zeggenschap en medebeslissingsrecht voor verpleegkundigen, betere arbeidsvoorwaarden en -contracten, goede loopbaanpaden en meer ontwikkelmogelijkheden. Tot in 2021 !

\section{Familie- participatie tijdens corona}

\author{
TREFWOORDEN \\ $\rightarrow$ Ziekenhuiszorg \\ $\rightarrow$ Familieparticipatie \\ $\rightarrow$ Corona
}

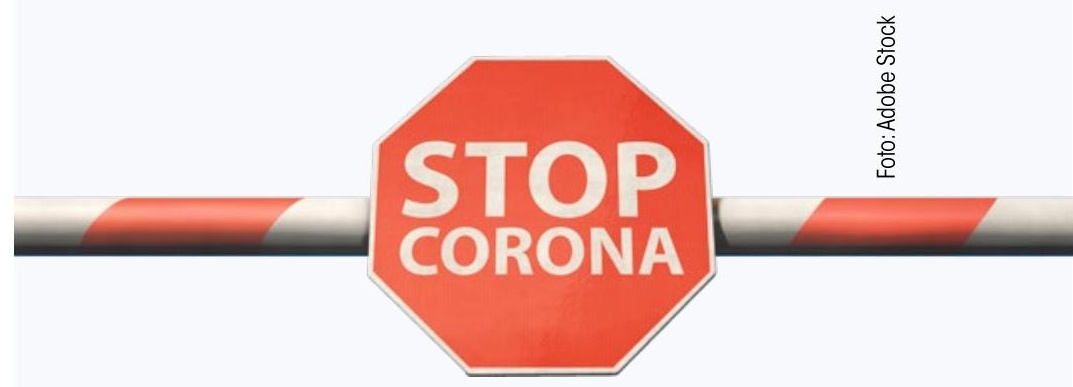



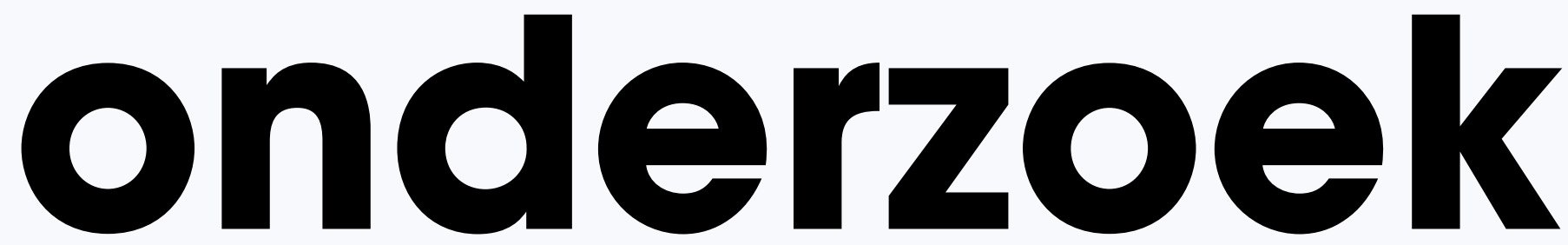

Wat te doen wanneer contact tussen

ziekenhuispatiënten en familie niet

vanzelfsprekend is, zoals tijdens het

begin van de COVID-19-uitbraak in

2020? De auteurs hebben een lijst met

aanbevelingen opgesteld van en voor

verpleegkundigen.

auteurs

IRENE JONGERDEN

JOLANDA MAASKANT

JANNEKE BIK

MARJA

STORM-VERSLOOT

MYRTHE JOOSTEN

SELMA MUSTERS

JOKE WIELENGA

ANNE ESKES

De auteurs zijn

werkzaam bij

Amsterdam UMC (a)

CORRESPONDENTIE

IRENE JONGERDEN

I.JONGERDEN@

AMSTERDAMUMC.NL
Tijdens de COVID-19-uitbraak in het voorjaar van 2020 is het bezoek in ziekenhuizen drastisch ingeperkt. Speciaal ingerichte COVID-afdelingen hanteerden veelal een bezoekersstop. Een begrijpelijke maatregel, die echter ook vragen opriep bij verpleegkundigen: hoe kunnen zij in coronatijd invulling geven aan familieparticipatie? Hoe kunnen ze familie adequaat informeren en ondersteunen? Met de FAM-coronastudie, een kwalitatief onderzoek, wilden we concrete adviezen kunnen geven over familieparticipatie in situaties waarin dit niet vanzelfsprekend is.

Participatie van familie in de zorg krijgt in toenemende mate een plek in ziekenhuizen. Bij familieparticipatie gaat het om een respectvolle samenwerking tussen patiënt, familie en zorgverleners, die zich uit in gedeelde besluitvorming en het delen van informatie en verantwoordelijkheid. ${ }^{1-2}$ Er is steeds meer wetenschappelijke onderbouwing dat familieparticipatie in het ziekenhuis klinische uitkomsten positief beïnvloedt. Zo leidt betrokkenheid van familie in de zorg tot minder angstige en depressieve gevoelens én een verhoogde mate van tevredenheid over de zorg bij de patiënt en familie. ${ }^{3}$ Verder geeft familieparticipatie meer werktevredenheid bij verpleeg- kundigen, terwijl het stress en burn out vermindert. ${ }^{3}$

Vanwege de COVID-19-pandemie in het voorjaar van 2020 scherpten ziekenhuizen de bezoekersregeling aan. Het gevolg was dat de mogelijkheden tot familieparticipatie werden beperkt. Op speciaal ingerichte COVID-afdelingen gold veelal een algehele bezoekersstop, om het risico op besmetting te beperken en de schaarse beschermende middelen te sparen. Deze aanpassing had enorme consequenties voor het contact met familie. Verpleegkundigen werkzaam op COVID-afdelingen ervaarden problemen toen 'real-life-communicatie' met familie niet meer mogelijk was. Ze vroegen zich af hoe ze familie toch

\section{'Delier of angst kreeg minder aandacht dan temperatuur en labwaarden"}

adequaat konden informeren en ondersteunen. In de FAM-coronastudie hebben we de ervaringen van verpleegkundigen in de eerste COVID-periode geëxploreerd. Verder is de opgedane kennis omgezet in concrete aanbevelingen over hoe vorm te geven aan familieparticipatie in situaties waarin contact met een familie niet vanzelfsprekend is.

\section{WERKWIJZE}

Om inzicht te krijgen in het familiecontact tijdens de eerste COVID-periode, hebben we in het voorjaar van 
2020 een kwalitatieve studie gedaan. Allereerst hebben we een dossieronderzoek uit- gevoerd naar inhoud en wijze van familiegerelateerd contact. We hebben 189 dossiers doorgenomen van volwassen patiënten die tussen 23 maart en 26 april 2020 waren opgenomen op een van de COVID-verpleegafdelingen (niet IC) van Amsterdam UMC (locaties AMC en VUmc). Concreet houdt dit in dat alle rapportages gescreend werden op opmerkingen die betrekking hadden op familie(contact). Notities die gemaakt waren tijdens een eventuele IC-opname werden niet meegenomen. De bevindingen van het dossieronderzoek werden vervolgens besproken in twee online focusgroepen. Negen verpleegkundigen, die ten minste vier dagen op een van de CO-

VID-afdelingen hadden gewerkt, deelden hun ervaringen en gaven

aanvullende input over wat zij nodig achtten om het familiecontact te optimaliseren.

Alle data zijn geanalyseerd volgens de Rapid and Rigorous Qualitative Data Analysis (RADaR) Technique for Applied Research. ${ }^{4}$ Met deze techniek konden we snel en gestructureerd kwalitatieve data analyseren en de belangrijkste bevindingen rapporteren.

\section{RESULTATEN}

De meeste patiëntendossiers waren van mannen (64 procent) met een gemiddelde leeftijd van 63 jaar (SD 13), die gemiddeld vijf dagen waren opgenomen op een COVID-19 afdeling. Zestien patiënten (8 procent) zijn overleden op de afdeling. De belangrijkste thema's die naar voren kwamen op basis van de analyses van de patiëntendossiers en focusgroepen lichten we nader toe.

\section{Veranderingen in communicatie met familie}

Veel contact met familie op de COVID-afdelingen verliep via telefoon en videobellen. Het contact varieerde per afdeling: op sommige afdelingen belde een arts of verpleegkundige op onregelmatige tijden of werd het initiatief bij de familie gelegd om te bellen voor informatie.

'De meeste mensen die er lagen waren zo ziek, eerste prioriteit is patiënt zelf en daarna dacht je: oh ja er is nog familie die we moeten bellen.' (Focusgroep)

Op andere afdelingen verliep het contact met familie gestructureerd via zogenaamde supportteams: teams van artsen en verpleegkundigen die op de IC specifiek de taak hadden het contact met de familie te onderhouden. Zij

\section{TABEL 1 AANBEVELINGEN VOOR CONTACT MET FAMILIE IN SITUATIES WAARIN DIT NIET VANZELFSPREKEND IS (VOOR VOLLEDIG OVERZICHT: ZIE WWW.TVZDIRECT.NL)}

\begin{tabular}{l|l}
\hline Aanbeveling & Toelichting \\
\hline $\begin{array}{l}\text { Zorg voor een structuur voor } \\
\text { contact }\end{array}$ & $\begin{array}{l}\text { Communicatie met en participatie door familie is, zoals wellicht } \\
\text { verwacht tijdens de COVID-19 uitbraak, sterk gewijzigd. Het contact } \\
\text { met familie verliep veelal telefonisch en niet gestructureerd, terwijl } \\
\text { een vaste systematische structuur als wenselijk wordt gezien door veel } \\
\text { verpleegkundigen. }\end{array}$ \\
\hline $\begin{array}{l}\text { Zorg voor een vast } \\
\text { rapportageformat met daarin } \\
\text { pandacht voor lichamelijke, } \\
\text { aspecten }\end{array}$ & $\begin{array}{l}\text { De focus in het contact lag op het informeren van familie over de } \\
\text { lichamelijke conditie van de patiënt en het medisch beleid. Een vast } \\
\text { rapportageformat met daarin ook aandacht voor psychosociale en } \\
\text { emotionele uitingen van de familie in relatie tot de toestand van de } \\
\text { patiënt kan verpleegkundigen helpen ook deze kant van de zorg niet uit } \\
\text { het oog te verliezen. }\end{array}$ \\
\hline $\begin{array}{l}\text { Betrek familie actief bij angst of } \\
\text { delier }\end{array}$ & $\begin{array}{l}\text { Betrek familie actief ter voorkoming van angst of delier. Als dit niet } \\
\text { mogelijk is met fysieke aanwezigheid, gebruik dan videobellen. }\end{array}$ \\
\hline $\begin{array}{l}\text { Investeer in voldoende } \\
\text { communicatiemiddelen }\end{array}$ & $\begin{array}{l}\text { Het is van belang dat afdelingen investeren in voldoende } \\
\text { communicatiemiddelen en verspreiding hiervan breed bekendmaken, } \\
\text { zodat zorgverleners op de hoogte zijn, want gebruik van deze } \\
\text { hulpmiddelen is niet vanzelfsprekend. Verpleegkundigen hebben } \\
\text { behoefte aan een duidelijke instructie die proactief aangeboden wordt. }\end{array}$ \\
\hline
\end{tabular}

waren niet betrokken bij de directe zorg, maar waren wel aanwezig bij de overdracht en haalden overige informatie uit het patiëntendossier. Dit contact liep soms door na overplaatsing van IC naar een COVID-verpleegafdeling. Verpleegkundigen gaven aan dat ze de vaste structuur die de supportteams boden als erg waardevol ervaarden.

Verpleegkundigen vonden de beschikbaarheid van telefoons en tablets, evenals vaardigheden om deze te gebruiken, belangrijke voorwaarden voor het contact met familie. In principe waren op alle afdelingen tablets beschikbaar, hoewel niet iedereen daarvan op de hoogte was. Daarnaast voelden niet alle verpleegkundigen zich zeker in het gebruik van de tablets.

\section{Focus op lichamelijke conditie}

Uit het dossieronderzoek bleek dat veel contact met familie gericht was op de lichamelijke conditie van de patiënt of op het te voeren beleid. Hierbij ging het vooral om actuele informatie over COVID-19-parameters, zoals saturatie, temperatuur en labwaarden, en om korte-termijnprognose (stabiel, herstellend, verslechterend).

Verpleegkundigen in de focusgroepen bevestigden dat de focus lag op de lichamelijke conditie, óók vanuit de familie, die vaak vroeg naar ademhaling en saturatie. Andere gezondheidsproblemen kregen veel minder aandacht. Informatie over de geestelijke gesteldheid van patiënten, zoals delier of angst, werd beperkt gemeld.

'Wat ik bemerkte was dat we de patienten een beetje als dezelfde soort patiënten gingen zien, en dat er voornamelijk heel veel aandacht werd besteed aan hoeveel zuurstof heeft iemand, wat is z'n saturatie, wat is $z$ 'n ademhaling. Al het andere, waar een patiënt ook nog uit bestaat, zoals doorliggen, het sociale gedeelte of onderliggend lijden, was naar de achtergrond gezonken.' (Focusgroep)

\section{Betrokkenheid afhankelijk van condi- tie patiënt \\ Betrokkenheid van familie bij de zorg beperkte zich vaak tot praktische zaken, zoals het brengen van schone kleding of eten. De betrokkenheid}




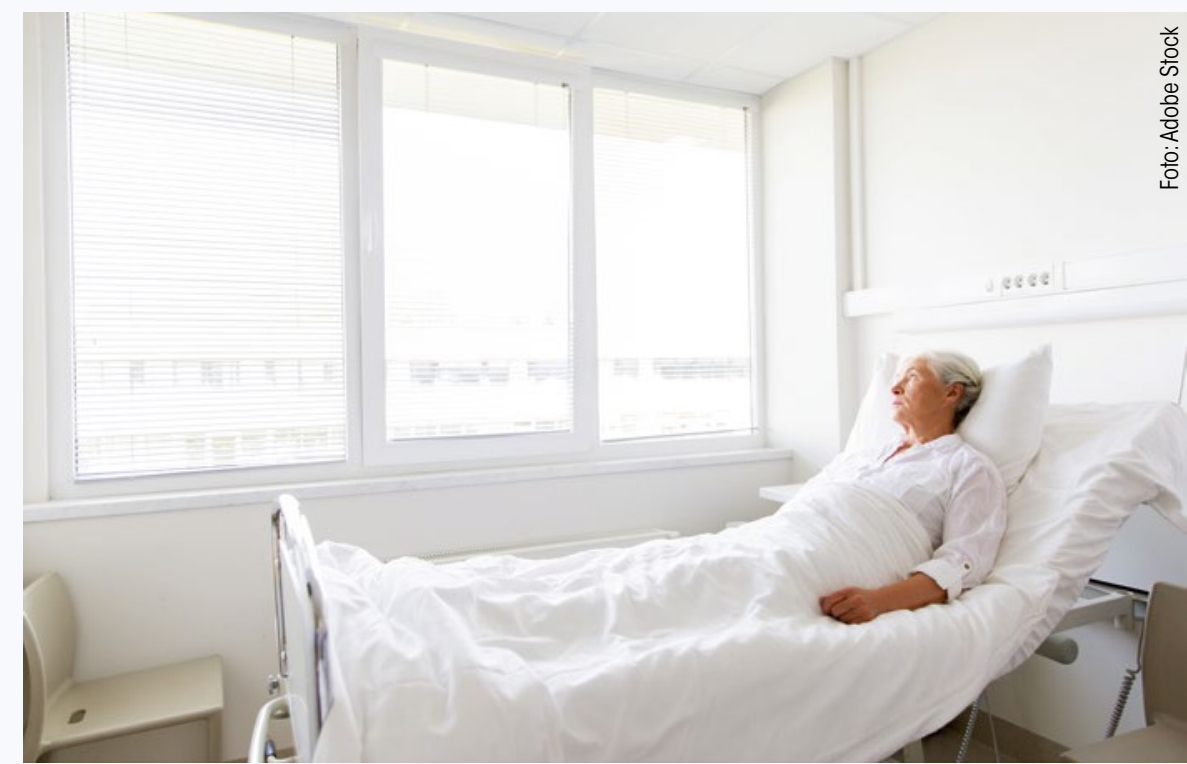

werd groter wanneer de conditie van de patiënt verslechterde, bijvoorbeeld als die terminaal was. Dan werden uitzonderingen gemaakt op de beperkingen in bezoek.

'Zeker in de laatste levensfase. Dan wil je niets liever dan dat er familie bij is. Dat geeft je zelf een fijn gevoel, dat er iemand continu aanwezig is, mocht zij [patiënt] op dat moment komen te overlijden.' (Focusgroep)

Bij patiënten die delirant of angstig waren, werd soms melding gemaakt van de inzet van familie via videobellen. Verpleegkundigen gaven nadrukkelijk aan in dergelijke situaties de familie te missen.

'Niet alleen bij de laatste fase, ook als ze naar de IC gingen had de familie angst kunnen wegnemen. Als familie erbij was geweest, was de ervaring misschien minder traumatisch geweest. Dat was achter-

\section{'Sommige ver- pleegkundigen vonden het rus- tig dat familie er niet was'}

af ook wel veel waard geweest.' (Focusgroep)

\section{Dilemma's door beperkingen in contact}

Verpleegkundigen gaven aan dat er duidelijk minder contact met familie was dan voor de COVID-pandemie. Dit werd door verpleegkundigen wisselend ervaren. Sommigen gaven toe dat ze het aanwezig was. Hierdoor konden ze zich volledig richten op de intensieve en conprettig en rustig vonden dat familie niet

\section{Samenvatiing \\ $\rightarrow$ De COVID-19 pandemie heeft een \\ enorme impact gekend op familiepar- \\ ticipatie in ziekenhuizen. \\ $\rightarrow$ Door beperking in bezoek ver- \\ minderde het contact met familie \\ drastisch en kwam de focus vooral te \\ liggen op de lichamelijke conditie. \\ $\rightarrow$ In situaties waarin familiecontact \\ niet vanzelfsprekend is, adviseren we}

gestructureerd contact, inclusief een format voor rapportage waarin zowel fysieke als psychosociale en emotionele aspecten van patiënt en familie worden genoteerd.

$\rightarrow$ We adviseren ook professionals te trainen in mogelijkheden van digitale communicatie. tinu veranderende patiëntenzorg en op de veranderingen in beleid en in teamsamenstelling door COVID. Bovendien waren er zorgen over de risico's op besmetting van familie. Aan de andere kant ging het tegen het gevoel van verpleegkundigen in om bezoek te beperken, zeker wanneer een patiënt kwam te overlijden. In dergelijke situaties maakten verpleegkundigen uitzonderingen.

'Het gaat zo enorm tegen je gevoel in, iemand is in de laatste fase van zijn leven, en jij gaat zeggen er mogen maar één of twee familieleden bij. Maar er zijn vaak uitzonderingen gemaakt, te vaak.' (Focusgroep)

\section{PRAKTISCHE AANBEVELINGEN}

Op basis van het dossieronderzoek en de ervaringen uit de focusgroepen hebben we een lijst met aanbevelingen opgesteld van en voor verpleegkundigen. De belangrijkste aanbevelingen zijn genoemd in tabel 1 . Een complete lijst van de aanbevelingen en ervaren barrières staat op www.tvzdirect.nl. De aanbevelingen kunnen gebruikt worden om in je team en met familie het gesprek aan te gaan over het contact met familie op momenten dat dit niet vanzelfsprekend is: hoe geven jullie dit vorm, wat zijn de wensen van patiënt en familie en hoe kun je dit met elkaar verbeteren?

We bedanken Isabel Degenhart, Corien Eeltink, Melina van Gunsteren, Roos Keulers en Noor Rouw voor hun hulp bij de dataverzameling. We bedanken ook de verpleegkundigen die meededen aan de focusgroepen voor het delen van hun ervaringen.

\section{REFERENTIES}

1. Gasparini R, Champagne M, Stephany A, e.a. Policy to practice: increased family presence and the impact on patient- and family-centered care adoption. JONA. 2015;45(1):28-34.

2. Institute for Patient- and Family-Centered Care.

3. Park M, Giap TT, Lee M, e.a. Patientand family-centered care interventions for improving the quality of health care: $A$ review of systematic reviews. Int J Nurs Stud. 2018;87:69-83.

4. Watkins DC. Rapid and Rigorous Qualitative Data Analysis: The "RADaR" Technique for Applied Research. Int J Qual Meth. 2017;16(1). 